\title{
Lessons about Boundaries and Reciprocity in Rural-based Preceptorships
}

Olive Yonge

University of Alberta, olive.yonge@ualberta.ca

Florence Myrick

University of Alberta, amyrick@ualberta.ca

Linda M. Ferguson

University of Saskatchewan, linda.ferguson@usask.ca

Quinn Grundy

University of California, San Francisco, quinn.grundy@gmail.ca

Follow this and additional works at: https://qane-afi.casn.ca/journal

Part of the Education Commons, and the Nursing Commons

\section{Recommended Citation}

Yonge, Olive; Myrick, Florence; Ferguson, Linda M.; and Grundy, Quinn (2015) "Lessons about Boundaries and Reciprocity in Rural-based Preceptorships," Quality Advancement in Nursing Education - Avancées en formation infirmière: Vol. 1: Iss. 2, Article 4.

DOI: https://doi.org/10.17483/2368-6669.1002

This Article is brought to you for free and open access by Quality Advancement in Nursing Education - Avancées en formation infirmière. It has been accepted for inclusion in Quality Advancement in Nursing Education - Avancées en formation infirmière by an authorized editor of Quality Advancement in Nursing Education - Avancées en formation infirmière. 


\section{Lessons about Boundaries and Reciprocity in Rural-based Preceptorships}

\section{Cover Page Footnote}

Acknowledgements: We gratefully acknowledge our research assistants Jim Cockell MA and Judy McTavish BSc for their contributions to this study. Funding: The study was funded by the Social Sciences and Humanities Research Council of Canada [SSHRC 410-2008-1420 Yonge]. Remerciements : Nous remercions chaleureusement nos assistants à la recherche Jim Cockell, M.A. et Judy McTavish, B.Sc. pour leur contribution à cette étude. Financement : Cette étude a été financée par le Conseil de recherches en sciences humaines du Canada [CRSH 410-2008-1400, Yonge]. 


\section{Introduction}

It is evening in a small town in Saskatchewan. A junior hockey game is underway at the local arena, and a player is facedown on the ice. Jean, an acute care registered nurse (RN) having just finished her shift, hurries out from the stands to tend to him. A few days later, the injured player's family thanks her with meat from their freezer.

This scenario, based on events reported by research participants, illustrates the complexity of client-caregiver relationships in rural settings. Living and working in isolated communities with low population density, limited resources, and economies based on primary industries such as farming and natural resource extraction, rural nurses share a common code with their fellow community members. This code-based on reciprocity, independence, and an insider-outsider dialectic of us and them (Long \& Weinert, 2010)-permeates every aspect of rural life. For rural nurses, the code amounts to the constant negotiating of professional and personal boundaries amongst clients who are also neighbours, friends and family; and participation in a reciprocal, tacit economy of payment in kind.

Statistics Canada (2009) considers all "persons living outside centers with a population of 1,000 and outside areas with 400 persons per square kilometer"-approximately one fifth of the Canadian population - to be rural. For the purposes of health care, a rural community can be defined as a population no greater than 10,000 living no closer than 80 kilometers (49.7 miles) to a major regional hospital (Van Hofwegen, Kirkham, \& Harwood, 2005). The World Health Organization (2010) recently proposed a set of initiatives aimed at mitigating the scarcity of health professionals working in rural and remote areas. Among these initiatives are strategies to provide students of the health professions with educational experiences in rural settings, to provide rural health care workers with professional development and financial incentives, and to create a supportive climate for rural professional practice. A number of studies have recommended rural preceptorship placements as a recruitment strategy (Bushy \& Leipert, 2005; Neill \& Taylor, 2002; Van Hofwegen et al., 2005). For students undertaking such preceptorships, prior contextual knowledge of rural life and rural health care is beneficial.

Over an eighteen-month period between 2009 and 2010, the researchers conducted a photovoice study wherein they recruited four senior $\left(4^{\text {th }}\right.$ year $)$ nursing students and their four rural preceptors (nurse educators) to document their experiences of teaching and learning through photographs and narration. This participatory action research method (Wang \& Burris, 1997) resulted in a firsthand, visual narrative of rural nursing and clinical experiences-a compelling means of promoting nursing careers in rural settings for new graduates. This article explores how preceptorship conveys two central principles of rural role management: boundaries and reciprocity.

\section{Review of Literature}

Little is known about the capacity of preceptors to educate nursing students in rural role management, but the effect of community ethos on rural nursing practice has been explored to a modest degree. The competing scripts of health care policy and kinship or community bonds exemplify the classic opposition of Gemeinschaft (community) and Gesellschaft (society) values (Tönnies, 1887/2002). Rural health care has always relied on community voluntarism, but this may be less a matter of community-mindedness than a concession to the breakdown of formal care provision (Skinner, 2008). Amongst rural nurses, a cross-sectional survey revealed that sense of community is central to quality of life (Kulig et al., 2009). Reciprocal giving between 
rural nurses and their clients can be seen as social capital, with broad implications for holistic care and community health (Lauder, Reel, Farmer, \& Griggs, 2005). Jackman, Myrick, and Yonge (2010) point out that rural nurses practise a form of holistic care that extends to social and political activism on behalf of their communities.

Like their patients, rural nurses are obliged by circumstance to become highly independent, adapt to low-tech environments, develop broad skill sets, and cope with a high degree of recognition in the community (Bushy \& Leipert, 2005, Long \& Weinert, 2010). Rural nurses must become adept at managing multiple, overlapping roles as community members and advocates, as health care professionals and, inevitably, as patients (Kilpatrick, Cheers, Gilles, \& Taylor, 2009; Long \& Weinert, 2010; Mills, Francis, \& Bonner, 2007). Moules, MacLeod, Thirsk, and Hanlon (2010) observe that public health nurses in rural communities must be "exquisitely attuned to having and using power, keeping confidences, and setting and crossing boundaries" (p. 332).

In keeping with the overall aims of understanding and optimizing rural, precepted teaching and learning, this article illustrates how rural, clinical experiences teach nursing students to balance the requirements of health care policy, such as confidentiality, impartiality, and scope of practice, with competing community values such as neighbourliness and informality. Boundaries and reciprocity are explored as two predominant aspects of this rural role management.

\section{Aims}

\section{Method}

The aims of this study were (a) to construct a firsthand narrative of rural nursing and rural preceptorship through the thematic analysis of photovoice data; and (b) to gain a deeper understanding of the rural, precepted teaching and learning experience and ways to optimize it.

\section{Design}

Photovoice is a type of participatory action research (PAR) wherein the lived experience of community members is captured through their photographs, narration, and input into data analysis. Conventional photovoice methodology places central importance on the "facilitator," a community expert who acts as the researchers' liaison and as a recruiter, trainer, discussion leader, and advocate to the community (Wang \& Burris, 1997). The current study, however, focused on a relatively small number of participants dispersed across a wide geographical area, in a professional context with which the principal researchers were already well acquainted as nursing instructors and previous preceptorship coordinators. Members of the research team thus undertook the functions of the facilitator, on the basis of their familiarity with rural nursing and the students' nursing program. Coding and thematic analysis (Drew, Duncan, \& Sawyer, 2010) were employed in the construction of narrative.

Photovoice can elicit tacit cultural knowledge about abstract concepts such as "rural" (Leipert \& Anderson, 2012; Wendling, DeDoner, Schmidt, Calhoun, \& Jarvis, 2005). Moreover, its media-rich data are ideally suited to compelling, message-driven outcomes such as exhibitions, photographic essays, and digital stories. While the use of photovoice to document rural health care is not without precedent-Wendling et al. (2005) derive a number of themes pertaining to nursing students' perceptions of rurality - it should be emphasized that the scope of the current study is significantly broader. 


\section{Ethical Considerations}

In advance of the study, the researchers obtained ethical approval from 1) their respective university Human Research Ethics Boards; 2) the Deans or Designates of their respective Faculties of Nursing; and 3) each site at which the research took place. Maintaining participant privacy and anonymity is particularly challenging in photographic research (Catalani \& Minkler, 2010; Harrison, 2002); accordingly, research team members spoke with a medical photographer to better appreciate the ethical sensitivity of taking pictures in health care settings.

In one-to-one meetings with participants at the time of recruitment, the project coordinator verbally explained the photovoice study, its purpose, and ethical clearance. The researchers required participants to sign a release to the rights and ownership of the data produced, and advised them they would be free to withdraw at any time. Moreover, the researchers advised participants that they assumed responsibility for acquiring written photographic consent from all persons taking pictures-or appearing as subjects thereindestined for inclusion in the study. Further ethical measures were taken during project orientation sessions, as described below.

\section{Participants}

Members of the research team and clinical instructors recruited nursing students enrolled in their senior clinical practica; these individuals subsequently recruited their nurse preceptors to take part. Following the withdrawal of one preceptor, the sample comprised four students (one female and one male in Saskatchewan, and one female and one male in Alberta) and four, female preceptors (one working in acute care and one in home care in Saskatchewan, and two working in acute care in Alberta). Two of the preceptors had been practising for less than five years, while the other two had been practising for more than ten. In Saskatchewan, preceptorships were split between community care and acute care settings, while the Alberta rotations took place in acute care sites only. The male students commuted to sites within $100 \mathrm{~km}$ (62 mi) of their homes, while the female students took placements in their home communities.

The researchers carried out project orientation through multiple sessions at each site. Beyond the students and preceptors already recruited, these sessions were open to all onsite professionals, from physicians to housecleaners, who all gave their consent to participate on either side of the camera. The researchers emphasized that everyone was welcome to take his or her turn at becoming "photojournalists for [their] rural hospital, to show the rest of the health care world what rural health care is like." The sessions also addressed photographic ethics and power structures (Wang \& Burris, 1997), procedures for obtaining consent from photographic subjects, criteria for inclusion of photographs as data, ownership of images, operation of the digital cameras, and basic photographic techniques.

At four of the six sites, the participants $(n=8)$ further recruited colleagues, friends and family members to take pictures using the cameras supplied by the researchers. This approach yielded over 800 images encompassing a geographical area of hundreds of square kilometers.

\section{Data Collection}

Data collection took place across four acute and two community care sites (together with the surrounding rural landscapes) in Alberta and Saskatchewan. All participants-plus colleagues, family members, and friends whom they recruited in turn-took photographs using the inexpensive 10-12 megapixel digital cameras supplied. The researchers' only criterion was to tell the story of rural teaching and learning in photographs and words, over the duration of the 
clinical practicum.

Collection was organized into two phases: 1) a four-week orientation period, in which the researchers asked participants to document the outer face of their culture as much as possible in their photographs, concluding with an onsite, group discussion facilitated by members of the research team; and 2) four weeks of deeper photographic exploration of various themes, issues, and theories that emerged from the midpoint discussion, as per Wang and Burris (1997), concluding with another onsite, group discussion. In both discussions, the researchers elicited their participants' commentary on their photographs through open-ended questions such as "what do we see here?" and "what does this photo mean to you?" (Hergenrather, Rhodes, Cowan, Bardhoshi, \& Pula, 2009). All discussions, totalling 12.5 hours of recorded audio, were transcribed and added to the dataset.

\section{Data Analysis and Validation}

In keeping with the principles of participatory research (Wang \& Burris 1997), participants were responsible for selecting photographic content for inclusion as data, according to their discretion. Following the endpoint discussions at each site, the researchers imported over 800 photographs and accompanying discussion transcripts into NVivo 8 (qualitative analysis software) for coding and thematic analysis (Fereday \& Muir-Cochrane, 2006). This process involved the assigning of data to nodes or clusters representing prevalent themes, for example "teamwork," "making do," and "coping and supporting." The researchers then consolidated these nodes into a model that could account for the entire dataset: rural nurse preceptors act as clinical instructors and community gatekeepers, who teach students how to balance clinical practice with community mindedness.

To corroborate and legitimize their findings (Feredey \& Muir-Cochrane, 2006, p. 7) the researchers created a PowerPoint slideshow, grouping the participants' images and remarks according to the thematic nodes described above. This slideshow was presented to participants at the various sites, who supplied two types of feedback: (a) internal replication, whereby they reaffirmed and/or expanded upon their own previous statements; and (b) external replication, whereby they corroborated the experiences reported by participants at other sites. By thus triangulating the data between the various sites, the researchers achieved rigour. These validation sessions were also transcribed and imported into NVivo 8 to further develop the model.

\section{Findings}

The researchers found that rural preceptorships teach nursing students about the integration of professional and community ethos-specifically, the permeable boundaries between work and personal life, and a reciprocal give-and-take of complimentary goods and services. The following images are captioned with their authors' comments, made during group discussions with the researchers. 


\section{Professional-Personal Boundaries}

The opening account of a registered nurse (RN) providing after hours, on-ice care to an injured hockey player illustrates how regular traversal of the margin between professional and personal life is taken in stride. "A huge part of our family life is hockey," this RN remarked later on as she scrolled through a series of junior hockey photos; "[my son] played against the top [players] in the province." In providing after hours care to injured players, she was tracking between her dual roles as RN and hockey mom. It could just as easily have been her son lying injured on the ice.

Figure 1

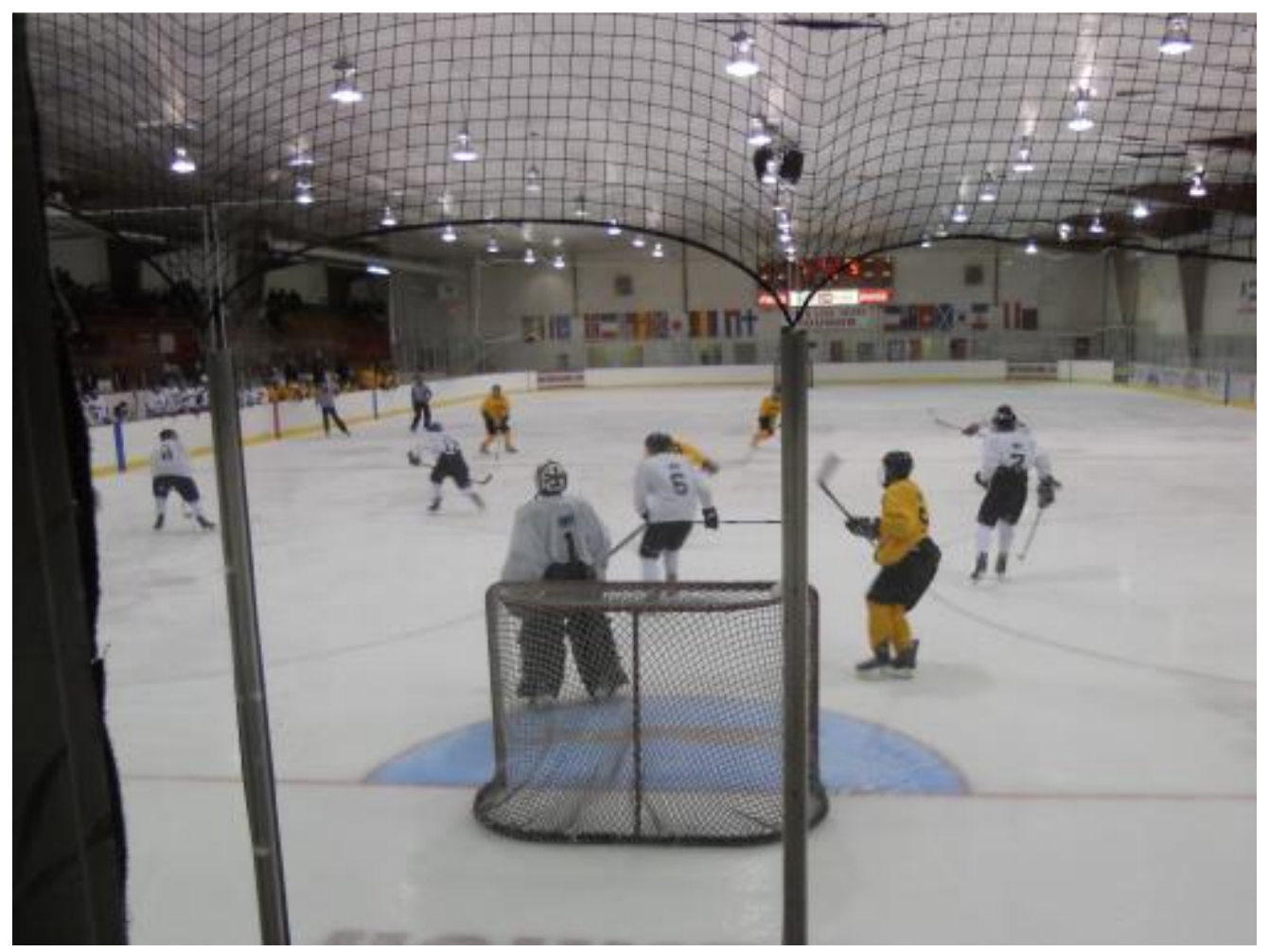

"Many times, I just got off shift, came down to a watch a game, someone's hurt, and I'm out on the ice. Many, many, many times." (Jean, preceptor)

Other nurse preceptors acknowledged a similar mutability of roles in the community, without complaint. "People come knock on my door to ask me to look at stuff," said another participating RN. "I look at it and say, 'I can't give medical advice, but go up [to the hospital]' . . . usually if they're bringing them to me, they're serious enough that they have to [go] up." Perennially being called upon for one's professional expertise outside the bounds of the work environment could be a source of pride. "Nursing staff have a tremendous amount of respect [in the community]," remarked a student who went on to describe his community health preceptorship on a First Nations reserve as "transformational." One of his classmates echoed the 
sentiment: "You watch your behaviour [in the community] because you don't want people to look badly upon nurses."

The corollary to being recognized and called upon as a nurse in the community is familiarity with clients as neighbours, friends, and family. "You do know the [client's] history, and their family history," said an RN, "[and] they know you, and your family dynamics. It gets to be quite touchy-feely sometimes; you have to wade your way through." In some instances, this personal connection to clients was felt to enhance the quality of care. One home care RN took pictures of her elderly father-in-law because, as she said, "When I look at him I think of all my other clients . . . in their homes and with their families. If it wasn't for home care, our clients would all be in long-term care." Other aspects of client recognition could be more difficult:

We find that we know everybody. When people are walking in from a car accident, we know them. When there's a teenager badly injured in a rollover, that's probably our kid's best friend. And yet you still have to go in there and deal with the parents, and do what you can. That is one of the downsides to rural nursing. (Acute care RN)

Remaining professionally detached in such circumstances was an acknowledged challenge for every preceptor who took part in the study. One $\mathrm{RN}$, a relative newcomer to her community, was mindful of the stress brought about by personal connections:

I know the more I live here and the more I know people, it's going to get harder, because I see the staff that have worked here ... it's hard, when you have somebody in Palliative Care that you know, and have become attached to, not to give them all the extra attention and extra time, because that's something that is due. And you see that a lot here, because they're families, and that family's been friends with my family for a long time, and so on.

\section{Reciprocity: The Tacit Economy}

If rural nurses accept the diffusion of their professional roles into community life, and vice versa, it is because they rely on other rural residents to reciprocate. Examples described by the nurse preceptors included:

- the local Royal Canadian Mounted Police (RCMP) officers, who provided their personal mobile phone numbers for after hours emergencies, saying "if you don't care what I look like, I can be there in four minutes flat";

- security personnel ("they fold linen, they make beds, they do everything"); and

- ambulance workers ("if I had an emergency... and I was scared, I would be calling these guys").

For any provider of goods or services, the consequence of living in a small, close-knit community is accountability to clients, not merely as a professional but as a fellow resident. Students and preceptors cited this repeatedly as an advantage of rural life. "A bonus to [living in] a small center is you usually know who's taking care of your kids, whereas in . . . big cities, you don't really know," said a student who chose to do her acute care practicum in her hometown. 
The implication was clear: I expect no less from my neighbours than they do from me.

Figure 2

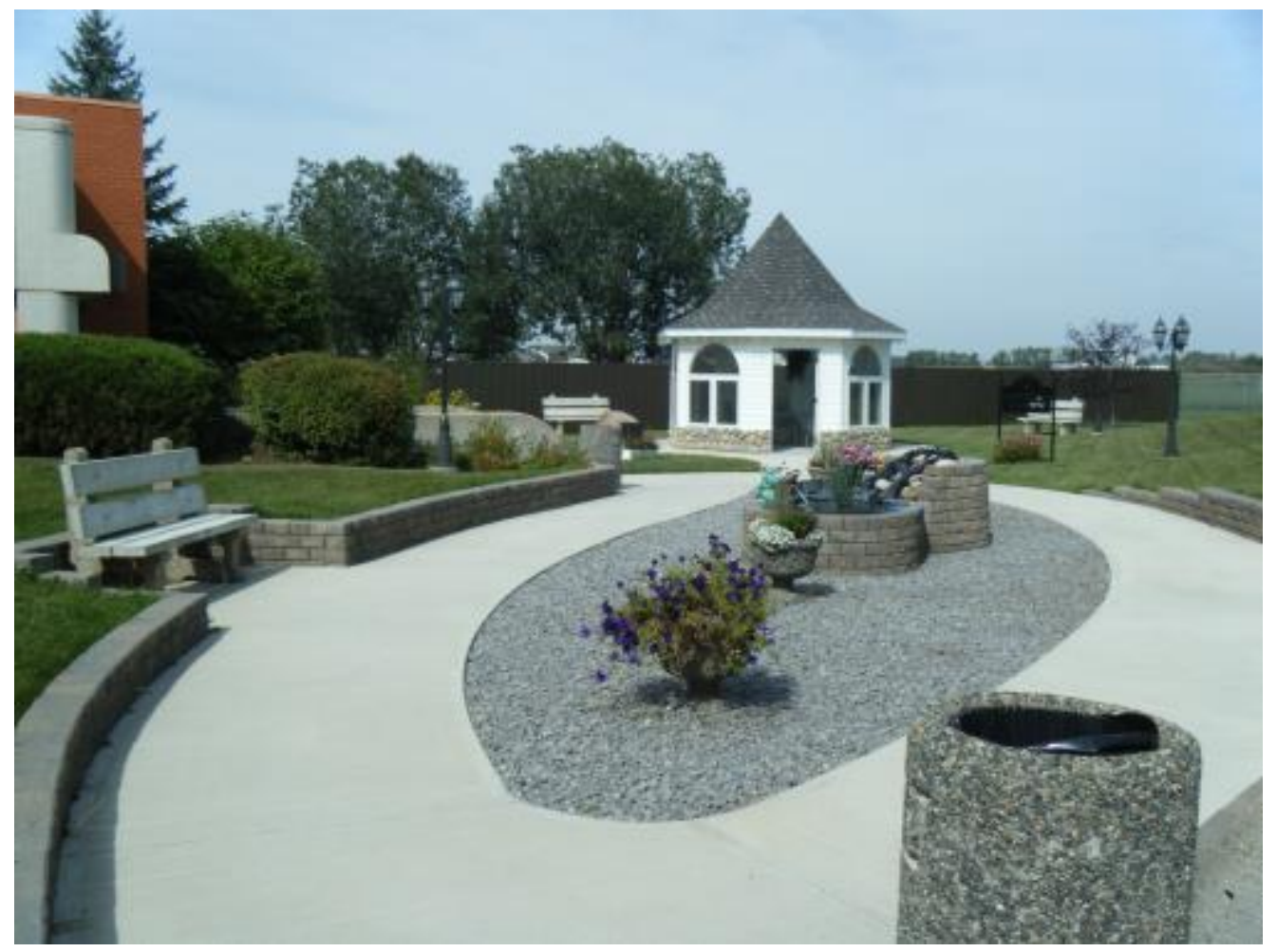

"This garden was all donated by [a local] family, and it's maintained by a volunteer. He mows the lawn...and he comes in the spring and gets all the beds ready. He's amazing. ... All the windows on Medicine face it, and all the windows on this side of Surgery face it." (Anita, preceptor)

In the thematic analysis of the photovoice data, "going above and beyond" and "giving and giving back" emerged as central precepts of the rural code. Gifts of time, labour, goods, and services - to say nothing of wealthier residents' financial largesse - are central to the moral and material sustenance of rural communities and their health care providers. One RN took a picture of the local fire hall in recognition of the volunteer firefighters who "donate back every penny they make to buy their equipment." Another RN took a picture of a two-storey farmhouseturned-restaurant, donated to the community by a celebrity former resident. A third took a picture of an ornamental garden, donated by a prominent local family and tended by a volunteer, located on the grounds of the hospital where she worked.

On a smaller scale, no less appreciated by nurses and their students, were personal gestures by appreciative community members. Preceptors and students described chocolate bars, flowers, and bags full of garden vegetables routinely pressed into their hands, particularly by home care clients. "Everyone's so appreciative because you've driven half an hour out to see them and pour them medications or help them with their dressing," marvelled a student. 
Figure 3

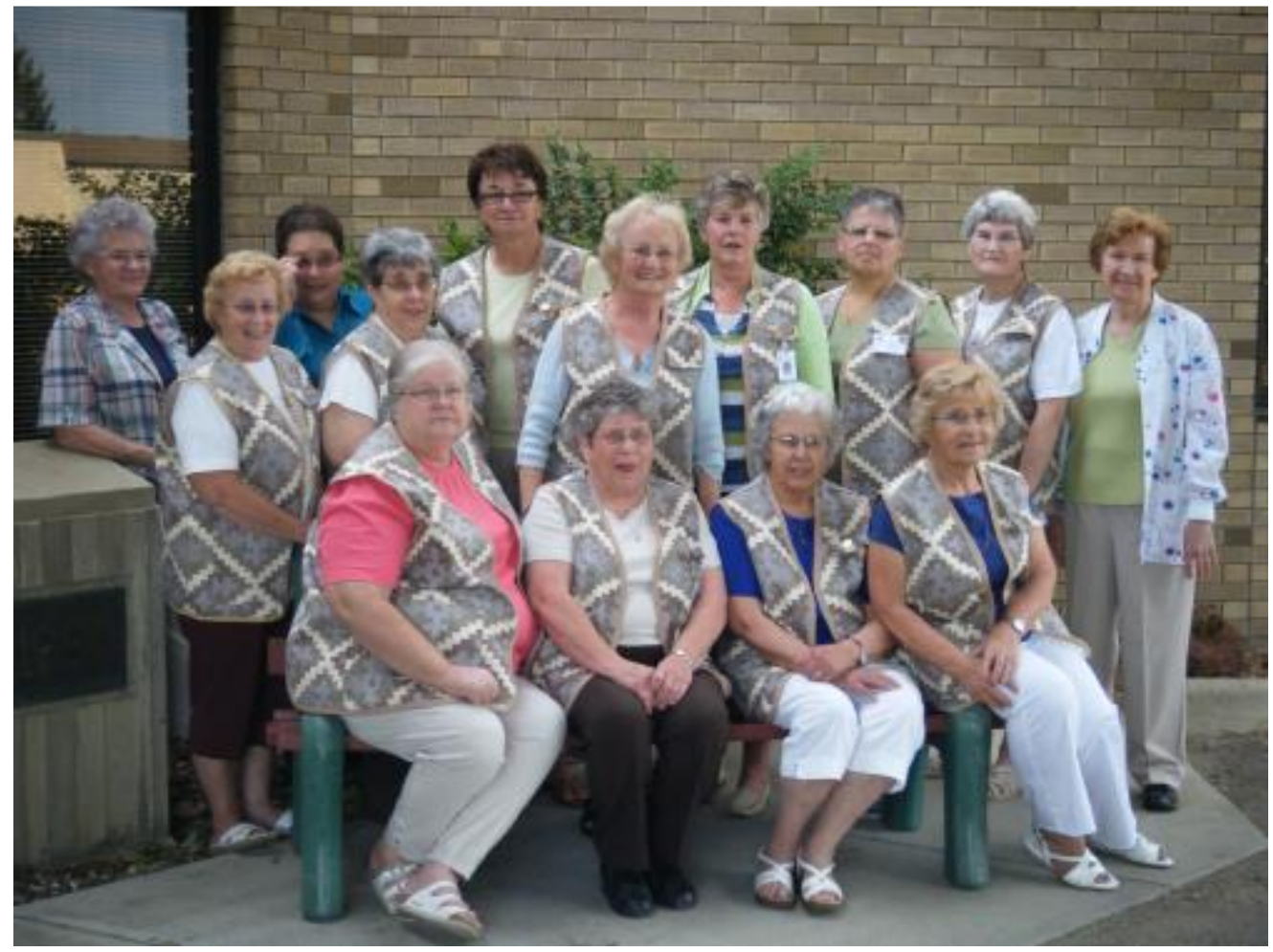

"These are our volunteer ladies. They come in on, say, Canada Day, and make really cute little items to put on all the trays. They fundraise for us. If we have somebody who just needs to be sat with, or someone needs to be fed and we are going crazy, quite often these ladies will come up. We can call on them." (Leslie, preceptor)

Community volunteers often supplied vital support to the health care setting itself. "They fundraise for us," one RN explained, commenting on a photograph of the hospital women's auxiliary; "if we have somebody who just needs to be sat with, or someone needs to be fed and we are going crazy, quite often these ladies will come up, we can call on them." Low population density and isolation, serious impediments to health care delivery in all rural and remote communities, also led to increased reliance on volunteers. "They knew he doesn't have much money," said one student of an outpatient with a badly infected leg, documented in a series of shots. "There's a volunteer service that comes and picks him up, and it's great; I can actually follow through and see him." As her home care preceptor added, "You get attached to these people."

\section{Discussion}

These findings regarding boundaries and reciprocity are consistent with the rural nursing studies cited above, with one additional, crucial layer of perspective: the firsthand, photographic account of rural preceptorship by those directly engaged in teaching and learning. This perspective has considerable implications for nursing faculties preparing students, particularly those with urban backgrounds, for rural health care placements. The give-and-take of rural, interpersonal relationships is not easy for outsiders to decipher. Role diffusion and multiple role management are facts of life for many professionals in rural areas (Mills et al., 2007; Long \& 
Weinert, 2010), but students observing role diffusion among nurses, security, police officers, and other professionals are likely to experience the dissonance of Gemeinschaft and Gesellschaft (community and society; Tönnies, 1887/2002). Judged through the lens of an urban-based nursing curriculum, after-hours care by RNs or informal security work by off-duty police officers might be considered boundary crossing or procedural violation. In the context of the reciprocal, tacit economy, however, such interactions are simply donations of time and expertiseneighbourly gestures akin to the gifts of produce given to nurses by grateful farmers. Lauder et al. (2006) note that community care nurses, both urban and rural, are often obliged to "hide" their off-duty work from disapproving managers (p. 76), even though such transactions are part of a system of social capital, especially integral to rural care (Lauder et al., 2006). The value of such capital in terms of holistic community wellness, at once palpable and yet difficult to quantify, is necessary contextual information for nursing students undertaking rural placements. Photovoice enabled participants in this study to illuminate and elucidate these phenomena, in the context of teaching and learning.

While Skinner's (2008) view of rural voluntarism as necessitated by a gradual breakdown of formal care may be valid, the nurse preceptors quoted above encouraged their students to regard volunteering as part of a cycle of reciprocal giving, central to rural community ethos. This is consistent with Kulig et al.'s (2009) finding that sense of community is of paramount importance to rural nurses. As with many aspects of the rural landscape photographed by participants-old train stations refurbished as teahouses and gift shops; wood frame grain elevators alongside massive inland terminals; powwows, parades, and seniors' square dancesgift exchanges resonate with the local history of the First Nations and European settlers. More important, gifts also encode the personal bonds between residents as neighbours, family, and friends. Much of what one participating RN refers to as "wading through" the awkward, "touchyfeely" thicket of interpersonal connections with her patients is accounted for in such gestures. Accepting gifts from patients-and caring for them outside the bounds of one's practice setting - is also part of the unspoken rural code, and the system of social capital which sustains community wellness (Lauder et al., 2006). The participants' photographs and remarks manifest this principle as they experienced it.

Given that the rural code is the cultural norm for preceptors, they may not even think to address customary behaviours, such as the need for reciprocity, with students. A number of studies recommend rural experience and/or the inclusion of rural-specific content in nursing curricula for students, prior to selecting practicum placement (Bushy \& Leipert, 2005; Edwards, Smith, Courtney, Finlayson, \& Chapman, 2004; World Health Organization, 2010; Yonge, Ferguson \& Myrick, 2006). The findings, moreover, tend to support the inclusion of community health or home care in the course of any rural nursing practicum, regardless of focus. Knowing from the outset that rural caregiving and community life are interwoven, whatever the chosen practice setting, may help to empower the coming generations of rural nurses.

\section{Limitations and Strengths}

Senior nursing students undertaking rural practica represent a sparse cohort in Western Canada; the four students taking part in this study were the only students opting for such placements in their given year, at the institutions included in the study. This factor, together with the wide geographic distribution of the practicum sites, necessarily limited the sample size and thus the generalizability of the findings. However, the researchers' primary aims of constructing a firsthand narrative through the thematic analysis of photovoice data, and gaining a deeper 
understanding of preceptorship, were arguably better served by a rich dataset emphasizing depth rather than breadth. Hundreds of images and hours of commentary, plus the triangulation of findings between sites, enabled the researchers to build a comprehensive, valid portrait of these particular participants' experiences.

\section{Conclusion}

An understanding of community ethos-to which permeable boundaries and reciprocity are central-is crucial for prospective rural nursing recruits. To that end, photovoice has proven to be an effective research tool both in drawing out tacit community knowledge and in making findings accessible to educators and students. The researchers are eager to see further exploration of the issues pertaining to multiple role management and reciprocity in rural nursing. 


\section{References}

Bushy, A., \& Leipert, B. (2005). Factors that influence students in choosing rural nursing practice: A pilot study. Rural and Remote Health, 5, 387.

Catalani, C., \& Minkler, M. (2010). Photovoice: A review of the literature in health and public health. Health Education \& Behavior, 37(3), 424-451. doi:10.1177/1090198109342084

Drew, S., Duncan, R., \& Sawyer, S. (2010). Visual storytelling: A beneficial but challenging method for health research with young people. Qualitative Health Research, 20(12), 1677-1688. doi:10.1177/1049732310377455

Edwards, H., Smith, S., Courtney, M., Finlayson, K., \& Chapman, H. (2004). The impact of clinical placement location on nursing students' competence and preparedness for practice. Nurse Education Today, 24, 248-255. http://dx.doi.org/10.1016/j.nedt.2004.01.003

Fereday, J. \& Muir-Cochrane, E. (2006). Demonstrating rigor using thematic analysis: A hybrid approach of inductive and deductive coding and theme development. International Journal of Qualitative Methods, 5(1), 1-13.

Harrison, B. (2002). Seeing health and illness worlds- using visual methodologies in a sociology of health and illness: A methodological review. Sociology of Health \& Illness, 24, 856872. doi:10.1111/1467-9566.00322

Hergenrather, K., Rhodes, S., Cowan, C., Bardhoshi, G., \& Pula, S. (2009). Photovoice as community-based participatory research: A qualitative review. American Journal of Health Behavior, 33(6), 686-698. http://dx.doi.org/10.5993/AJHB.33.6.6

Jackman, D., Myrick, F., \& Yonge, O. (2010). Rural nursing in Canada: A voice unheard. Online Journal of Rural Nursing and Health Care, 10(1), 60-69.

Kilpatrick, S., Cheers, B., Gilles, M., \& Taylor, J. (2009). Boundary crossers, communities and health: Exploring the role of rural health professionals. Health \& Place, 15, 284-290. doi:10.1016/j.healthplace.2008.05.008

Kulig, J., Stewart, N., Penz, K., Forbes, D., Morgan, D., \& Emerson, P. (2009). Work setting, community attachment, and satisfaction among rural and remote nurses. Public Health Nursing, 26(5), 430-439. doi:10.1111/j.1525-1446.2009.00801.x

Lauder, W., Reel, S., Farmer, J. \& Griggs, H. (2006). Social capital, rural nursing and rural nursing theory. Nursing Inquiry, 13(1), 73-79. doi: 10.1111/j.1440-1800.2006.00297.x

Leipert, B., \& Anderson, E. (2012). Rural nursing education: a photovoice perspective. Rural and Remote Health, 12, 2061.

Long, K., \& Weinert, C. (2010). Rural nursing: Developing the theory base. In C. A. Winters \& J. H. Lee (Eds.), Rural Nursing: Concepts, Theory and Practice (pp. 3-17). New York: Springer.

Mills, J., Francis, K., \& Bonner, A. (2007). Live my work: rural nurses and their multiple perspectives of self. Journal of Advanced Nursing, 59(6), 583-590. doi:10.1111/j.13652648.2007.04350.x

Moules, N., MacLeod, M., Thirsk, L., \& Hanlon, N. (2010). "And then you'll see her in the grocery store": The working relationships of public health nurses and high-priority families in northern Canadian communities. Journal of Pediatric Nursing, 25(5), 327334. 
Neill, J., \& Taylor, K. (2002). Undergraduate nursing students' clinical experiences in rural and remote areas: recruitment implications. Australian Journal of Rural Health, 10, 239-243. doi:10.1016/j.pedn.2008.12.003

Skinner, M. W. (2008). Voluntarism and long-term care in the countryside: the paradox of a threadbare sector. The Canadian Geographer 52(2), 188-203. doi:10.1111/j.15410064.2008.00208.x

Statistics Canada. (2009). Population urban and rural, by province and territory. Ottawa, ON: Government of Canada.

Tönnies, F. (1887/2002). Community and Society [Gemeinschaft und Gesellschaft] (C. Loomis, Trans. \& Ed.). Dover, England: Dover Publications.

Van Hofwegen, L., Kirkham, S., \& Harwood, C. (2005). The strength of rural nursing: Implications for undergraduate nursing education. International Journal of Nursing Education Scholarship, 2(1). doi:10.2202/1548-923X.1142

Wang, C., \& Burris, A. (1997). Photovoice: Concept, methodology, and use for participatory needs assessment. Health Education and Behavior, 24(3), 369-387. doi:10.1177/109019819702400309

Wendling, L., DeDoner, J., Schmidt, L., Calhoun, J., \& Jarvis, K. (2005). Learning through shared meaning: Nursing students' perceptions of rural Kansas. The Kansas Nurse, 80(5), $1-3$.

World Health Organization. (2010). Increasing access to health workers in remote and rural areas through improved retention. Geneva: World Health Organization.

Yonge, O., Ferguson, L., \& Myrick, F. (2006). Preceptorship placements in western rural Canadian settings: Perceptions of nursing students and preceptors. Online Journal of Rural Nursing and Health Care, 6(2). 